\title{
MEMÓRIAS DA EDUCAÇÃO EM ASTRONOMIA NO BRASIL: RECORTES A PARTIR DAS FALAS DE PESQUISADORES ENTREVISTADOS SOBRE O TEMA
}

Gustavo Iachel ${ }^{1}$

Roberto Nardi ${ }^{2}$

\begin{abstract}
Resumo: Relata-se neste artigo uma retrospectiva histórica referente a dados provenientes de pesquisa em Educação em Astronomia no país, pós 1973, organizada com base na análise das falas de pesquisadores considerados referências nacionais nesse campo, como também na leitura de publicações das áreas de ensino de Ciências, Física e Astronomia. Tal panorama histórico foi desenvolvido com o intuito de favorecer nossa compreensão sobre os contextos nos quais os pesquisadores entrevistados se desenvolveram profissionalmente. Ademais, buscou-se recobrar a memória do crescente campo de pesquisa em Educação em Astronomia no país. Entendemos que o histórico apresentado possa contribuir para com os que buscam entender o passado na tentativa de solucionar demandas atuais e futuras.
\end{abstract}

Palavras-chave: Educação em Astronomia; Pesquisa em Ensino de Astronomia; Memórias de pesquisadores.

\section{MEMORIAS DE LA EDUCACIÓN EN ASTRONOMÍA EN BRASIL: RECORTES DE LOS DISCURSOS DE INVESTIGADORES ENTREVISTADOS ACERCA DEL TEMA}

\begin{abstract}
Resumen: Se presenta en este artículo una retrospectiva histórica referente a datos provenientes de la investigación en enseñanza de la astronomía en el Brasil, después de 1973, organizada sobre la base del análisis de los discursos de los investigadores nacionales considerados referencias en este campo, y también en la lectura de las publicaciones en las áreas de Enseñanza de las Ciencias, Física y Astronomía. Este repaso histórico se desarrolló con el fin de facilitar la comprensión de los contextos en los que los investigadores entrevistados se han desarrollado profesionalmente. Por otra parte, se intentó recuperar la memoria del creciente campo de la investigación en Educación en Astronomía en el país. Creemos que el relato presentado puede contribuir a quien trata de comprender el pasado, en un intento de resolver las demandas actuales y futuras.
\end{abstract}

Palabras clave: Educación en Astronomía; Investigación en Enseñanza de Astronomía; Memorias de los investigadores.

\section{MEMORIES OF ASTRONOMY EDUCATION IN BRAZIL: CLIPPINGS FROM THE DISCOURSES OF INTERVIEWED RESEARCHERS ON THE SUBJECT}

Abstract: This paper presents a historical retrospective concerning data from a research in Astronomy Education in Brazil, after 1973. It was organized on the basis of the speech analysis of national researchers considered references in this field by their peers. Furthermore, it was elaborated on the basis of other studies from the areas of Science Education, Physics and Astronomy. This historical overview was developed in order to facilitate understanding of the contexts in which the interviewed researchers have developed professionally. Moreover, we attempted to recover the memory of the growing field of research in Astronomy Education in the country. We believe that the history presented can help those trying to understand the past in an attempt to resolve current and future demands.

Keywords: Astronomy Education; Research in Astronomy Education; Memories of researchers.

\footnotetext{
${ }^{1}$ Universidade Estadual de Londrina, UEL, Londrina-PR. Email: <iachel@uel.br>.

${ }^{2}$ Universidade Estadual Paulista "Júlio de Mesquita Filho", UNESP, Bauru-SP.

Email:<nardi@fc.unesp.br>.
} 


\section{Introdução}

Em pesquisa recente (IACHEL, 2013), entrevistamos pesquisadores considerados, por seus pares, referências nacionais na pesquisa relacionada à Educação em Astronomia no Brasil. Investigamos suas concepções acerca da formação inicial e continuada de professores, bem como sobre o papel de possíveis centros de referência, como planetários e observatórios, na formação de professores em suas regiões. Além disso, pudemos constatar várias declarações que remontam à memória da pesquisa em Educação em Astronomia no país, que apresentamos e comentamos ao longo deste trabalho. Dentro da ampla pesquisa realizada, a elaboração da retrospectiva histórica teve por objetivo: i. Reconstruir a memória do campo de pesquisa em Educação em Astronomia no país; ii. Oferecer elementos históricos aos pesquisadores interessados em compreender o passado da área, principalmente àqueles que proporão possíveis ações na tentativa de suprir as demandas atuais e futuras, em relação à formação inicial ou continuada de professores.

\section{Metodologia de Pesquisa}

Através de buscas sistemáticas ao sistema de currículos Lattes, identificamos 93 doutores que se declaram atuantes na área de Astronomia Aplicada ou na área de Ensino ou Educação em Astronomia. Tais pesquisadores foram consultados com o intuito de indicarem, eletronicamente, três nomes que julgam pertencer a pesquisadores importantes na pesquisa em ensino de Astronomia no país. A pesquisa desenvolvida entrevistou sete entre os onze nomes mais indicados pela consulta.

As gravações das entrevistas em áudio foram autorizadas pelos participantes mediante a assinatura de termo de consentimento livre e esclarecido. A transcrição integral das entrevistas pode ser consultada na pesquisa que originou este artigo (IACHEL, 2013). Em relação a este artigo, foram selecionados apenas os trechos em que os entrevistados comentam sobre a história deste campo de pesquisa.

A partir da análise de suas falas, bem como da leitura de outros trabalhos da área, fomos capazes de elaborar a retrospectiva descrita. Visando elucidar de onde falam esses entrevistados, apresentamos alguns dados sobre os mesmos, sem, entretanto, identificá-los, visto os compromissos éticos firmados quando da tomada das entrevistas.

\section{Os pesquisadores entrevistados}

Para que a análise do conteúdo (BARDIN, 2000) proposta na pesquisa que originou este estudo fosse satisfatória (IACHEL, 2013), foi preciso que contextualizássemos os lugares de onde falam os pesquisadores entrevistados nesta pesquisa. Todavia, não poderíamos revelar a identidade dos pesquisadores participantes, conforme os princípios éticos de pesquisa pelos quais nos comprometemos. Com isso, realizamos o exercício de "dizer sobre" os entrevistados sem, no entanto, trazer elementos suficientes para a sua identificação.

É válido ressaltar que os pesquisadores entrevistados receberam siglas aleatórias (P1 até P7), como mostrado no Quadro 1. 


\begin{tabular}{|c|l|}
\hline Entrevistado & Formação \\
\hline P1 & $\begin{array}{l}\text { Doutorado em Educação (década de 90); atuante em universidade } \\
\text { pública; Dirigiu planetário; pesquisa sobre a Educação em Astronomia, a } \\
\text { Educação não formal e a formação continuada de professores. }\end{array}$ \\
\hline P2 & $\begin{array}{l}\text { Doutorado em ensino (década de 2000); atuante em universidade pública; } \\
\text { pesquisa sobre a Educação em Astronomia. }\end{array}$ \\
\hline P3 & $\begin{array}{l}\text { Doutorado em Educação (década de 2000); atuante em universidade } \\
\text { pública; pesquisa sobre a Educação em Astronomia, a formação de } \\
\text { professores e a prática de ensino de ciências e de Física. }\end{array}$ \\
\hline P4 & $\begin{array}{l}\text { Doutorado em Astronomia (década de 90); atuante em universidade } \\
\text { pública; pesquisa sobre o ensino de Física e de Astronomia. }\end{array}$ \\
\hline P5 & $\begin{array}{l}\text { Doutorado em Educação (década de 2000); atuante em universidade } \\
\text { pública; pesquisa sobre o ensino de Física e de Astronomia. }\end{array}$ \\
\hline P6 & $\begin{array}{l}\text { Doutorado em Astrofísica (década de 90); atuante em universidade } \\
\text { pública; pesquisa sobre a Astrofísica e o ensino de Astronomia. }\end{array}$ \\
\hline P7 & $\begin{array}{l}\text { Doutorado em Astronomia (década de 70); aposentou-se atuando em } \\
\text { universidade pública; dirigiu planetário; pesquisa sobre a História, o } \\
\text { ensino e a divulgação da Astronomia; colabora em pesquisas. }\end{array}$ \\
\hline
\end{tabular}

Quadro 1 - Formação dos entrevistados.

Fonte: Iachel (2013).

Objetivando verificar em que área os entrevistados realizam suas pesquisas, fizemos um estudo quanto ao tipo de suas publicações ao longo de seu percurso formativo.

Pudemos observar, por exemplo, que o P7 defendeu seus trabalhos de mestrado e doutorado na década de 1970, e que, nas décadas seguintes, contribuiu com artigos e capítulos de livros na área de pesquisa em Astronomia Aplicada. Entendemos, por essa razão, que sua indicação se deu muito mais por seu posicionamento ativista e sua atuação no debate, como vemos claramente em suas falas, do que por suas publicações, que são no campo da Astronomia Aplicada.

O mesmo ocorre com o P4 e o P6, que possuem doutorado em Astronomia (ambos defendidos na década de 90), mas que recentemente publicaram artigos no campo da Educação. Este fato nos faz imaginar que os professores doutores formados nas áreas aplicadas passam, de alguma forma, a participar dos debates em Educação. Os motivos que levam esses pesquisadores a migrar de área podem ser devidos, por exemplo, às demandas dos departamentos em que atuam, por motivações pessoais ou profissionais, por abertura do campo de pesquisa na área de ensino, visto haver, recentemente, um maior fomento para ações na área de Educação.

Entendemos que as contribuições no campo da pesquisa e do ensino em Astronomia realizadas por esses três primeiros pesquisadores devem-se muito mais às atividades de ensino e divulgação que realizam do que às suas publicações nesse campo 
específico. É possível que esse ativismo tenha sido considerado pelos consultados durante as indicações.

O P1 também optou por migrar de campo de atuação, pois se formou mestre em Física na década de 1980, e doutor em Educação na década de 1990. Seus trabalhos passaram, então, a ser publicados no campo da pesquisa em Educação, com ênfase no ensino de Astronomia.

O P2, o P3 e o P5 formaram-se mestres na área de Educação e depois defenderam o doutorado (década de 2000) na mesma área. Por essa razão, suas publicações são voltadas à área de Educação em Astronomia. Assim como no caso dos demais pesquisadores indicados, também são ativistas por realizarem ações próeducação em Astronomia, relacionadas principalmente à formação inicial e continuada de professores, além de contribuírem com publicações em periódicos da área de Ensino.

Estes dados auxiliaram-nos a verificar se a formação dos entrevistados possui características que possam interferir em suas concepções sobre o ensino de Astronomia, bem como sobre a formação inicial e continuada de professores. Considerando o estudo inicial de elementos da história da pesquisa em ensino de Astronomia no país e os perfis dos entrevistados, iniciamos a análise das entrevistas transcritas.

\section{Fatos históricos relacionados ao campo de Educação em Astronomia no país}

Inicialmente, organizamos um quadro síntese (Quadro 2) contendo fatos citados nas entrevistas e também decorrentes da pesquisa realizada (IACHEL, 2013) que julgamos relevantes neste percurso, o que nos possibilitou uma visão mais geral antes do detalhamento de cada momento. Para sua elaboração, nos concentramos nas falas dos entrevistados, bem como em registros presentes em atas de eventos, em boletins da Sociedade Astronômica Brasileira (SAB) e em relatos de outros pesquisadores. Utilizamos também bases de dados, como a organizada e mantida por Bretones e Megid Neto (2005), que nos auxiliou a localizar historicamente algumas teses e dissertações ao longo de quatro décadas. Apoiamos-nos também em consultas realizadas e organizadas por Feres (2010).

\begin{tabular}{|cl|}
\hline ANO & FATO \\
\hline 1973 & $\begin{array}{l}\text { Defesa da tese sobre o ensino de Física na área de Educação, de autoria de Rodolpho } \\
\text { Caniato. }\end{array}$ \\
1985 & $\begin{array}{l}\text { Durante o VI Simpósio Nacional de Ensino de Física (SNEF), em Niterói/RJ, o } \\
\text { professor Caniato apresentou o trabalho "Ideário e prática de uma proposta brasileira } \\
\text { para o ensino de Física", onde destaca o emprego da Astronomia. }\end{array}$ \\
1987 & $\begin{array}{l}\text { Durante o VII SNEF, os pesquisadores Romildo Póvoa Faria (que viria a participar } \\
\text { ativamente da estruturação dos PCN para o segundo ciclo do ensino fundamental), } \\
\text { Marcio Campos e Rodolpho Caniato debateram sobre o ensino de Astronomia no } 1^{\circ} \\
\text { grau. }\end{array}$ \\
\hline
\end{tabular}




\begin{tabular}{|c|c|}
\hline 1991 & $\begin{array}{l}\text { Realização de um grupo de trabalho sobre o ensino de Astronomia no } 1^{\circ} \text { e } 2^{\circ} \text { grau } \\
\text { durante o IX SNEF (São Carlos/SP), com elaboração de moção destinada à assembleia } \\
\text { do evento. }\end{array}$ \\
\hline 1993 & $\begin{array}{l}\text { Realização de um grupo de trabalho sobre o ensino de Astronomia no } 1^{\circ} \text { e } 2^{\circ} \text { grau } \\
\text { durante o X SNEF (Londrina/PR), com nova moção elaborada. }\end{array}$ \\
\hline 1993 & $\begin{array}{l}\text { Criação da Comissão de Ensino da Sociedade Astronomia Brasileira (CESAB) } \\
\text { durante a XXI Reunião Anual da SAB (Caxambu/RJ). }\end{array}$ \\
\hline 1996 & $\begin{array}{l}\text { Realização do I Encontro Brasileiro de ensino de Astronomia (EBEA) e I Reunião da } \\
\text { Associação Brasileira de Planetários (RABP), em Campinas/SP. }\end{array}$ \\
\hline 1998 & $\begin{array}{l}\text { Publicação dos Parâmetros Curriculares Nacionais (PCN); Criação da Olimpíada } \\
\text { Brasileira de Astronomia e Astronáutica (OBA). }\end{array}$ \\
\hline 1999 & $\begin{array}{l}\text { Durante o IV EBEA e IV RABP, que ocorreu no Rio de Janeiro, ocorreram debates } \\
\text { sobre a separação desses eventos. }\end{array}$ \\
\hline 2000 & $\begin{array}{l}\text { Criação da Área } 46 \text { da CAPES, que impulsionou a criação de mestrados, doutorados e } \\
\text { periódicos no campo de Ensino de Ciências. }\end{array}$ \\
\hline 2002 & $\begin{array}{l}\text { Último ano em que ocorreram simultaneamente o VII EBEA e o VII RABP, em } \\
\text { Fortaleza/CE. }\end{array}$ \\
\hline 2004 & $\begin{array}{l}\text { Realização do VIII e último EBEA, em São Paulo; Lançamento da Revista Eletrônica } \\
\text { Latino-Americana de Educação em Astronomia (RELEA). }\end{array}$ \\
\hline 2005 & $\begin{array}{l}\text { Organização de uma base de dados contendo informações sobre teses e dissertações } \\
\text { relacionadas ao ensino de Astronomia. }\end{array}$ \\
\hline 2009 & $\begin{array}{l}\text { Ano Internacional da Astronomia; Criação dos Encontros Regionais de ensino de } \\
\text { Astronomia. }\end{array}$ \\
\hline 2011 & $\begin{array}{l}\text { Retorno de evento específico relacionado ao ensino de Astronomia, o Simpósio } \\
\text { Nacional de Educação em Astronomia (SNEA). }\end{array}$ \\
\hline 2012 & Realização do II SNEA, amplamente consolidado. \\
\hline
\end{tabular}

Quadro 2 - Síntese da retrospectiva histórica da pesquisa em Educação em Astronomia no país.

Fonte: Iachel (2013).

Com base nesse panorama geral, debatemos, com maiores detalhes, momentos da história da pesquisa em ensino de Astronomia no país, apoiado também nos discursos dos entrevistados que puderam acompanhar o desenrolar desses fatos.

Inicialmente, destacamos a defesa da tese de Caniato (1973), de título "Um projeto brasileiro para o ensino de Física". Apesar de se tratar de um estudo sobre a Física geral, um dos volumes da obra, "o Céu", trouxe várias discussões sobre o ensino de Astronomia, apresentando possibilidades para a instrumentação em sala de aula. Para grande parte dos pesquisadores, incluindo-se alguns dos entrevistados, esse marco representa um momento em que as demais áreas das humanidades, como a da Educação, passaram a se preocupar mais com o ensino de Astronomia nas escolas, principalmente no que diz respeito à formação inicial de professores. 
P3: É. No Brasil tem poucos trabalhos que mostram as justificativas para o ensino de Astronomia. A primeira tese que apareceu, que é do professor Rodolpho Caniato, ele elenca algumas justificativas da Astronomia.

O P3 destaca o trabalho de Caniato (1985) como um dos primeiros a apresentar a importância do ensino de Astronomia no país. Existe certo consenso de que sua tese marque bem o provável início das discussões, das preocupações e dos movimentos de pesquisadores envolvidos com a Educação em Astronomia no país. Além de sua tese, os episódios de vida de "Joãozinho da Maré" (CANIATO, 1983) foram utilizados em cursos de formação inicial e/ou continuada por todo o país, ao longo de anos. Por esses e outros motivos, o professor é reconhecido pelos pares como pioneiro nesse campo de pesquisa.

Atualmente, este autor participa das discussões mais importantes sobre a pesquisa no país, vindo a proferir a palestra "Meus caminhos no ensino de Astronomia", durante o I SNEA (2011), no Rio de Janeiro, momento em que compartilhou sua experiência de vida com os colegas presentes:

Continuemos a semear, mesmo quando nos parecer que as sementes se perderam. Na Natureza é sempre assim: é preciso que haja muitas sementes e agentes semeadores para que umas poucas sementes vinguem. Considero um privilégio estar vivendo e vendo quantos outros semeadores estão preocupados e de fato também semeando por muitos outros novos campos, tanto ao Sol, como ao luar e também sob o céu estrelado (CANIATO, p.7, 2011).

Continuando a trilha histórica, nos deparamos com um debate entre os pesquisadores Romildo Póvoa Faria, Marcio Campos e Rodolpho Caniato realizado em 1987, durante o VII SNEF, sobre alguns conteúdos da Astronomia no então "primeiro grau" da escolaridade (hoje denominado ensino fundamental) e a formação de professores. Esse fato pode ter delimitado, de certa forma, um espaço para o debate do ensino de Astronomia dentro dos eventos da área de ensino de Física, o que provavelmente motivou o surgimento dos grupos de trabalho em encontros posteriores.

$\mathrm{Na}$ ocasião, os pesquisadores debateram sobre o ensino de Astronomia neste nível de ensino ( $1^{\circ}$ grau). Alguns anos depois, Romildo Póvoa viria a participar ativamente da estruturação dos PCN para o segundo e terceiro ciclos do ensino fundamental, fato lembrado por P5:

P5: [...] tínhamos uma pessoa no PCN de ciências muito... não sei se você conheceu o Romildo [Póvoa Faria], ele trabalhou muito anos no planetário de Campinas, uma pessoa fantástica que infelizmente já se foi. Ele foi o responsável por essa parte toda de Astronomia no PCN de ciências e ele, claro, sabia dessa formação do professor, mais frágil. Trabalhava muito diretamente com o público, e aí foi lá e escreveu um material que é quase um material didático.

Como vemos em uma seção posterior, a estruturação de um PCN preocupado com os conteúdos da Astronomia pode ter influenciado no aumento do número de pessoas interessadas na pesquisa em ensino de Astronomia. Todavia, em 1987, o número de trabalhos apresentados em eventos nacionais era baixo como, por exemplo, 
no VII SNEF, quanto foram apresentados apenas dois painéis sobre o tema (NASCIMENTO e HAMBURGER, 1987; LIVI, 1987).

Em 1991, foi organizado um grupo de trabalho sobre o ensino de Astronomia no $1^{\circ}$ e $2^{\circ}$ grau (atuais ensino fundamental e médio) durante o IX SNEF (São Carlos/SP). Dentre as discussões e atividades, destaca-se a moção encaminhada para a assembleia geral do evento:

Sendo o SNEF o foro de discussão para o ensino de Física, e reconhecendo que a Astronomia é parte integrante desse ensino com grande potencial de torná-lo mais dinâmico, crítico e criativo, solicitamos que o Simpósio constitua-se também no foro congregador de professores interessados em desenvolver o ensino de Astronomia, sugerindo que seja buscado o apoio da Sociedade Astronômica Brasileira para tal fim. Coordenador: Silvia Helena Becker Livi, relator: Marcos Cesar Danhoni Neves (NEVES, p.137, 1991).

Observamos, nesse momento do percurso histórico, que estamos analisando a vontade política de alguns envolvidos com o ensino de Astronomia no país em oficializar um espaço para um debate constante ao longo de eventos futuros.

Durante o X SNEF (NARDI, 1993), foi novamente reunido um grupo de trabalho sobre o ensino de Astronomia no $1^{\circ}$ e $2^{\circ}$ grau. Além de relatarem um "indiscutível AVANÇO na discussão do ensino de Astronomia em relação ao encontro no IX SNEF”, os envolvidos encaminharam nova moção à assembleia geral do evento:

Tendo o SNEF se tornado um foro congregador de professores interessados em desenvolver o ensino de Astronomia em $1^{\circ}$ e $2^{\circ}$ grau, tendo sido constatado que o ensino de Astronomia está ou vem sendo implementado no currículo do $1^{\circ}$ grau, como ocorreu recentemente no Estado do Paraná e, tendo em vista a insistência dos professores de $1^{\circ}$ grau presentes no encontro "ensino de Astronomia no $1^{\circ}$ e $2^{\circ}$ grau", solicitamos que seja encaminhada aos órgãos competentes (Secretaria de Educação dos Estados e Ministério da Educação), a RECOMENDAÇÃO de que o ensino de Astronomia seja incluído, não só nos cursos de aperfeiçoamento de professores, mas também nos currículos dos cursos de formação de professores $\left(2^{\circ}\right.$ grau, Magistério e Licenciaturas). (LIVI, p.97, 1993)

Desta vez, o movimento político buscava maiores mudanças na estrutura de formação inicial de professores, pois a inserção da Astronomia na escola já era um fato como, por exemplo, no estado do Paraná. Aparentemente, a recomendação não surtiu os efeitos esperados. Todavia, segundo Trevisan (2011), nesse momento consolidou-se um grupo preocupado com o ensino de Astronomia (GEA) que, ainda em 1993, expôs a necessidade da formação de uma comissão, denominada posteriormente de Comissão de Ensino da Sociedade Astronomia Brasileira (CESAB). O fato ocorreu durante a XXI Reunião Anual (Caxambu - RJ), cuja ata emitida em 1994 descreve: 
O Dr. Jafelice pede a palavra para discorrer sobre a necessidade de a sociedade criar uma comissão de ensino como prevê os estatutos. Referindo-se a mesa redonda sobre ensino havida, na noite anterior, explica que as discussões mostraram a necessidade de se promover outros eventos desse gênero. Usaram da palavra os Profs. Drs. Steiner e Vilhena encaminhando a favor da criação da referida comissão. $O$ Dr. Magalhães lembra que a referida comissão já existiu em outras épocas e que o importante é reunir esforços fomentando localmente as discussões. O assunto é encaminhado para votação ficando aprovada a formação de uma comissão de ensino e que a diretoria deverá em um primeiro instante elegê-la para dar continuidade às discussões a ela pertinentes, recomendando ainda a realização de encontros para abordar o assunto ensino como foi promovido nesta reunião anual (LEISTER, 1994, apud TREVISAN, sem paginação, 2011).

Estava assim oficializada a criação de uma comissão de ensino dentro da Sociedade Astronômica Brasileira. Os motivos que impulsionaram a criação da CESAB, segundo o $\mathrm{P} 4$, eram evidentes e inspiravam preocupações:

P4: [...] Não adiantava termos aí cerca de 200 ou 300 astrônomos profissionais fazendo pesquisa de ponta, com registros internacionais, e enquanto se reuniam anualmente, as escolas da cidade e do lugar estavam ensinando coisas completamente equivocadas.

Ao longo de duas décadas de existência, a CESAB passou por fases variadas, contribuindo de várias formas para a consolidação da pesquisa em ensino de Astronomia no país. Sobre isso, o P2 comenta:

P2: A comissão de ensino da SAB passou por várias fases, não é? Logo a primeira fase foi dizer na própria sociedade, ou estabelecer essa questão, de que fazer ensino não é só ensinar, mas também fazer pesquisa em ensino. É algo que temos falado. Agora, ao longo de muitos anos, a área de ensino da SAB foi praticamente sinônimo de OBA, mas também não é só isso. Não é só isso. Então, me parece assim, que na próxima gestão a gente atue um pouco mais de perto, mas é uma tarefa muito séria e de muito fôlego poder fazer uma política em nível nacional de colocar esse tipo de coisa que estou falando. Isso é uma tentativa, temos isso em mente, mas deve ter muito trabalho...

Três anos depois do X SNEF e da criação da CESAB, ocorreu o I EBEA (Encontro Brasileiro de Educação em Astronomia), em Campinas/SP. O evento foi realizado conjuntamente com as reuniões da Associação Brasileira de Planetários até a sua sétima edição.

Outro fator que consideramos haver contribuído para alavancar o número de pesquisas no campo de ensino de Astronomia no país é a publicação dos PCN em 1998:

O extenso documento que explicita a proposta de reorientação curricular para os anos finais do ensino fundamental, elaborado pela Secretaria de Educação Fundamental do MEC, foi publicado em 1998. É composto por dez volumes, organizados da seguinte forma: um é introdutório, oito são referentes às diversas Áreas de Conhecimento do terceiro e do quarto ciclos do ensino fundamental (Língua Portuguesa, 
Matemática, História, Geografia, Ciências Naturais, Educação Física, Arte e Língua Estrangeira), e o último volume trata dos Temas Transversais, que envolvem questões sociais relativas a: Ética, Saúde, Orientação Sexual, Meio Ambiente, Trabalho e Consumo e Pluralidade Cultural (BONAMINO e MARTÍNEZ, p. 11, 2002).

Por se tratar de um documento oficial, inferimos que sua elaboração tenha interferido positivamente no aumento de pessoas interessadas em pesquisar sobre o ensino desses conteúdos, e consequentemente no número de publicações, como mostrado pelo gráfico da Figura 1.

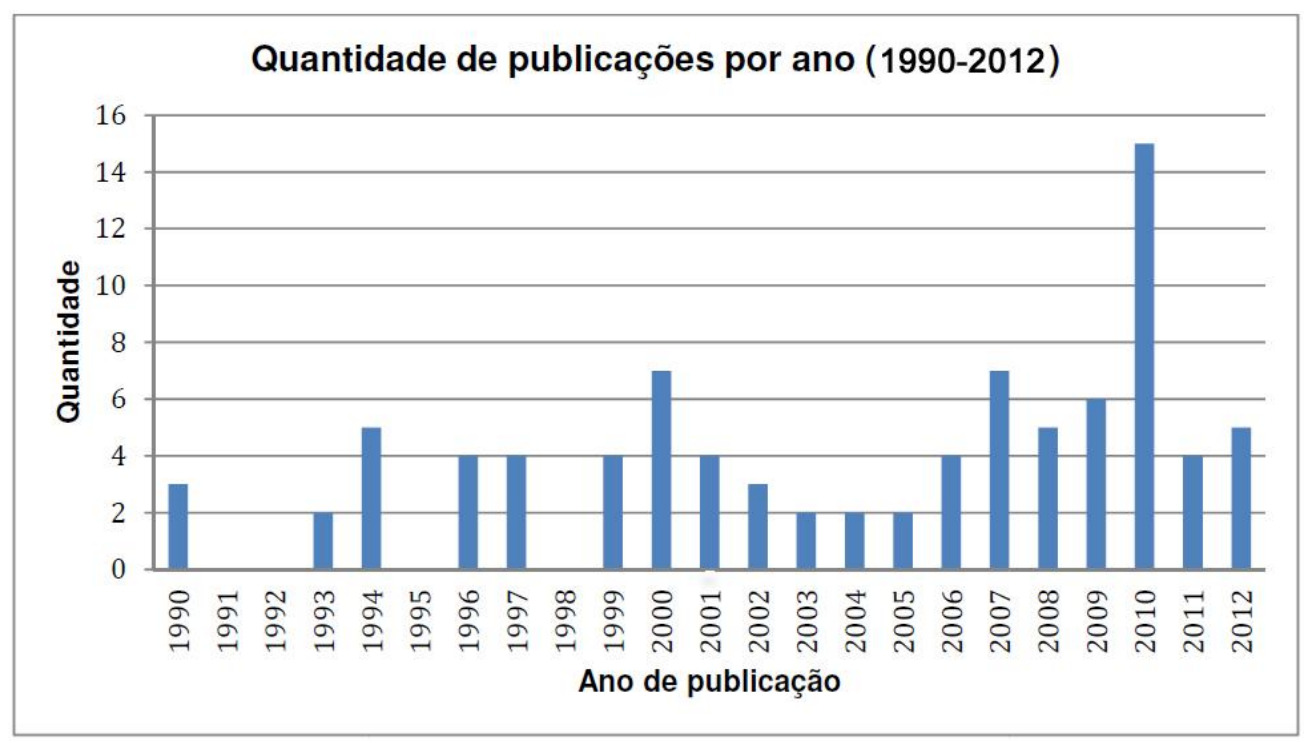

Figura 1 - Gráfico das publicações relacionadas ao ensino de Astronomia presentes no CBEF e na RBEF entre 1990-2012.

Fonte: Adaptado de Iachel e Nardi (2010).

Ainda em 1998, as atividades da CESAB convergiram para a criação da Olimpíada Brasileira de Astronomia e Astronáutica (OBA) a qual, assim, relata o P4:

P4: [...] nos permitiu atuar de uma forma muito mais ampla, com um alcance maior, pois ao envolver o aluno na olimpíada o seu professor também estará envolvido, e se o professor quer que seu aluno se saia bem na OBA, ele tem que se informar melhor, buscar mais informações, seja compartilhando essa busca com os alunos ou colocando as coisas em um mural na escola sobre o tema, depois de aplicada a prova vendo o gabarito, se surpreendendo com respostas que ele achava de repente certas e que foram indicadas no gabarito como erradas e entender por que. Tudo isso é um processo de aprendizagem, entendeu?

O P7 destaca também o papel da OBA:

P7: [...] aconteceram outras iniciativas de grande alcance e eu destaco aí, sem dúvidas, a Olimpíada Brasileira de Astronomia. Eu acho que é outro caminho, exatamente fugindo, eu acho, do sistema formal, é uma iniciativa não formal, porém colaborando com o sistema formal, que tem produzido uma sinergia muito positiva. Eu fico impressionado, quer dizer, acho que isso é uma demonstração de que há uma demanda reprimida e que a Olimpíada vem atender. Então, a boa receptividade da Olimpíada é uma resposta a uma demanda 
reprimidíssima de muito tempo e que cresce de uma maneira exponencial, e que tem tido sorte, por exemplo, com a coincidência do ano internacional da Astronomia, em que as atividades se multiplicaram.

O P2 também ressalta o papel da OBA, mas levanta igualmente uma preocupação:

P2: [...] a OBA faz um trabalho muito importante, mas imagino que ela não tenha uma preocupação mais geopolítica. São muito divulgados os trabalhos do professor Canalle, cursos, divulgação de material e tal, mas atende a quem quer fazer a OBA... e se o professor não quiser fazer a OBA? Como ele pode ser atingido, no bom sentido, como podemos disponibilizar em nível nacional esse material?

Também o P5 comenta sobre a OBA, destacando algumas de suas preocupações.

P5: [...] Acho que a OBA, embora tenha muita crítica as olimpíadas em geral, ela tem um papel de trazer mais gente, de fazer com que muitos professores no interior do país se envolvam com essa temática. Então, acho que têm surgido muito mais cursos de formação continuada, pois na formação inicial não temos nada. Então, se não tivermos formação continuada é impossível que a Astronomia chegue à sala de aula [...] As olimpíadas em geral têm essa característica de ser uma competição e não é um consenso de que a competição, você gerar esse sentimento de competição, seja algo benéfico do ponto de vista educacional, e isso em qualquer olimpíada, não só na OBA. Então, isso é uma crítica... tem também sobre o estilo da prova, sobre o estilo de questão que se tem privilegiado... pois, essas coisas, no fundo, se formos olhar isso como um vestibular, elas ditam regras também de como devem ser, então, se não temos um cuidado... isso depende muito de quem está fazendo a prova e sabemos que há muitos anos é o mesmo grupo, então não há diversidade. Acaba sendo algo muito linear.

Ostermann:

Tais preocupações foram tema de estudo recente realizado por Rezende e

A mentalidade que defende as olimpíadas científicas parece pautar-se na ideia de que a construção do conhecimento científico baseia-se na contribuição de talentos individuais. Este aspecto está cada vez mais questionado nas narrativas epistemológicas contemporâneas que veem a construção da ciência como coletiva e distribuída. Também a aprendizagem é cada vez mais aceita como um processo eminentemente social. A perspectiva sociocultural vem enfatizando seu caráter mediado por outros indivíduos e pela linguagem. Isso não quer dizer que o indivíduo não se desenvolva ou possa aprender sozinho, mas que precisa de algum tipo de mediação, exercida por um material ou por outro indivíduo. Além de possibilitar aprendizagem efetiva, a interação e a colaboração são valores defensáveis tanto do ponto de vista cognitivo ou educativo quanto do ponto de vista da formação humana. (REZENDE e OSTERMANN, 2012, p. 249)

Não teríamos condições materiais e temporais para avaliar a OBA e seu impacto relacionado ao ensino de conteúdos de Astronomia. Essa questão carece de pesquisas no país. Todavia, com base nos pontos de vista dos destaques mencionados, 
entendemos ser importante refletir sobre o papel da OBA na educação básica.

Inicialmente, preocupa-nos a carga de novas atribuições a qual o professor deverá aceitar, caso assuma coordenar as atividades em sua escola. Primeiramente, o docente deverá aprender os conteúdos da Astronomia, fato que dificilmente tem ocorrido na formação inicial. Após esse aprendizado, que poderá ocorrer em virtude de sua participação em atividades de formação continuada em horário extra e não remunerado, o professor deverá ser capaz de transpor didaticamente esse conhecimento e envolver seus estudantes em atividades de ensino. Quando o professor poderá ensinar conteúdos da Astronomia, além daqueles previstos pelos PCN? O docente, por fim, acabará tendo de destacar horário extra (e não remunerado, novamente) para montar turmas de alunos que desejam participar da OBA, para poder ensinar os conteúdos e ainda analisar, com eles, as edições anteriores. Enfim, o professor deverá estar muito motivado para participar da OBA, pois terá de investir um tempo extra, em que geralmente descansa de sua jornada semanal (normalmente extensa), para poder participar ativamente do processo. A questão nos remete àquela ideia de senso comum, segundo a qual o professor deva doar o seu tempo sempre que possível, um ranço secular, provavelmente jesuítico (ADORNO, 2006). Entendemos que o professor deve ser reconhecido como profissional e deva ser bem remunerado por qualquer atividade que desenvolva para o progresso de seus alunos ou de sua escola.

Por parte dos alunos, entendemos ser importante investigar e existe uma medida que permita examinar como e quanto uma vitória em uma olimpíada de conhecimento específico incentiva o vencedor a trilhar o caminho das ciências. Essa motivação dos vencedores nos parece momentânea, cabendo, em consequência disso, uma pesquisa envolvendo os vencedores das edições da OBA, para investigar por quais vias seguiram após a atividade. Caberia, ainda, uma investigação em relação aos estudantes que não foram vitoriosos nas edições da OBA em que participaram.

Por essas razões, apenas procuramos analisar os posicionamentos dos entrevistados em relação à criação e manutenção da OBA e, com isso, refletimos sobre algumas possíveis tensões entre os pontos de vista desses pesquisadores, analisando possíveis temáticas de pesquisas futuras sobre o tema.

Conforme vimos anteriormente, o $\mathrm{P} 4$ e o P7 possuem doutorado em Astronomia, enquanto que o P2 e o P5 possuem doutorado em Ensino e Educação, nesta ordem. Possivelmente, algumas tensões já partem da própria natureza e especificidade de suas formações. Acreditamos que um doutor em Astronomia seja capaz de refletir sobre o ensino de Astronomia, como evidenciado pela pesquisa. Todavia, os referenciais teóricos da Educação podem não ser compartilhados com as demais áreas, como a da Astronomia aplicada e vice-versa. Desta forma, as críticas sobre a natureza de uma competição entre alunos surgem de referenciais da Educação, leituras possivelmente desconhecidas por parte dos astrônomos profissionais que defendem e estruturam as olimpíadas.

Outro aspecto interessante no discurso do P5 diz respeito a questões políticas. Organizar provas de grande abrangência pode ser tido como um ato político, considerando-se que esses instrumentos ditam certos padrões, certas tendências aos conteúdos e às formas da Astronomia para a escola. Entende-se sua preocupação em razão de que o grupo responsável pela OBA, apesar de competente em Astronomia e Astronáutica, aparenta ser o mesmo desde a fundação da avaliação. Esse fato nos leva a 
imaginar que exista certa hegemonia entre cada edição da OBA, e é consenso que a hegemonia é um aspecto negativo por atrasar alguns avanços que a heterogenia traria à avaliação. Ademais, os avanços da pesquisa na área de ensino de Astronomia e em outras disciplinas relacionadas à Educação, de uma forma mais abrangente, precisam ser incorporados nesta questão.

Enfim, fica evidente que a formação dos envolvidos interfere diretamente em suas concepções, ora a favor, ora contra a OBA. Como dito anteriormente, nosso posicionamento em relação à existência e manutenção da OBA requer uma investigação profunda sobre o seu papel na formação dos alunos, professores e pesquisadores da área.

Voltando à retrospectiva histórica, podemos destacar dois trabalhos relevantes dessa linha de pesquisa: a tese de Bisch (1998) e a dissertação de Bretones (1999).

Durante o quarto Encontro Brasileiro de Educação em Astronomia (IV EBEA) e quarta Reunião da Associação Brasileira de Planetários (IV RABP), que ocorreram na cidade do Rio de Janeiro em 1999, alguns participantes se perguntavam se não seria vantajoso para ambos os eventos que eles ocorressem de forma separada, isto é, enquanto o EBEA atendesse a demanda de um grupo de profissionais mais interessados na Educação nos níveis fundamental, médio e superior, a RABP se destinaria aos profissionais ocupados com atividades desenvolvidas em planetários. Essas discussões amadureceram até 2002, quando se decidiu, durante a assembleia do sétimo encontro, em Fortaleza/CE, que os próximos eventos ocorreriam separadamente. Um dos organizadores do evento escreveu:

Finalmente a separação ocorreu em 2002, em Fortaleza, em um evento fraco em todos os níveis, sem nenhuma manifestação contrária, quando contamos com apenas 4 apresentações de trabalhos de ensino de Astronomia, sendo que apenas duas trouxeram temas adequados ao evento. Os eventos estavam se tornando caros, pois os organizadores esperavam a participação de cerca de 100 pessoas, no entanto, não compareciam mais de 30 pessoas e o público geral sumiu. (Apêndice A).

O Quadro 3 sintetiza os eventos EBEA e RABP que ocorreram de forma conjunta.

\begin{tabular}{|c|c|c|}
\hline Evento & Local & Data \\
\hline I EBEA e I RABP & Campinas / SP & $25-28 / 10 / 1996$ \\
\hline II EBEA e II RABP & Porto Alegre / RS & $08-09 / 11 / 1997$ \\
\hline III EBEA e III RABP & Belém / PA & $08-11 / 09 / 1998$ \\
\hline IV EBEA e IV RABP & Rio de Janeiro / RJ & $01-04 / 12 / 1999$ \\
\hline V EBEA e V RABP & Belo Horizonte e Ouro Preto / MG & $21-24 / 11 / 2000$ \\
\hline VI EBEA e VI RABP & Florianópolis / SC & $22-26 / 10 / 2001$ \\
\hline VII EBEA e VII RABP & Fortaleza / CE & $30 / 10-02 / 11 / 2002$ \\
\hline
\end{tabular}

Quadro 3 - EBEA e RABP.

Fonte: Relato histórico sobre os EBEAS (Apêndice A). 
Em 2004, realizou-se o oitavo e último EBEA na cidade de São Paulo. Infelizmente, o evento foi pouco procurado por professores e pelo público em geral, o que ocasionou a sua extinção. Isso nos mostra que, apesar das três décadas de pesquisa sobre o ensino de Astronomia no país, o grupo de pesquisadores interessados nessa linha ainda era pequeno.

Voltando ao ano de 2000, entendemos que a consolidação da área 46 na CAPES possa ter estimulado a criação de mestrados, doutorados e periódicos relacionados ao ensino de Ciências, campo em que a Educação em Astronomia pode contribuir e crescer. Segundo Nardi (2005), tal fato resultou da pressão dos pares, empenhados em congregar e avaliar os programas de pós-graduação existentes na época. Apesar de sua importância para a organização e articulação dos programas de pós-graduação em Ensino de Ciências no país, o conselho superior da CAPES extinguiu-a em 26/05/2011, criando a área de Ensino. Com isso, os programas que estavam cadastrados sob a área 46 foram agrupados aos demais programas de outras áreas específicas de ensino, como a da Física, da Química, da Matemática, da Saúde, do Direito etc., para serem cadastrados todos sob a área de Ensino. Entendemos que existem prós e contras em relação à extinção da área 46. Aparentemente, trabalhos da área de Ensino de Ciências são mais difíceis de serem classificados quanto à natureza dos conteúdos que investigam. Por exemplo, e este é o nosso caso, em que campo ou área o ensino de Astronomia deveria ser inserido? No de Ciências - se pensarmos na Astronomia do ensino fundamental e dos anos iniciais? No de Física - se abordamos a Astronomia ensinada no ensino médio? No da Astronomia e Astrofísica - se debatermos conteúdos mais avançados? Parece-nos vantajoso avançar melhorando nas possíveis classificações dos campos de pesquisa, sem com isso por obstáculos à possibilidade de interdisciplinaridade de tais disciplinas.

Continuando o percurso, podemos observar que, entre 2004 e 2009, houve certo silêncio por parte da comunidade quanto à realização de eventos com maior visibilidade, com exceção da contínua elaboração e aplicação da OBA. Todavia, o número de dissertações e teses sobre o tema no país saltou quantitativamente e qualitativamente. Dentre os vários trabalhos nesse período, destacaram-se na comunidade as dissertações de Langhi (2004), Mees (2004) e Marrone (2007), e as teses doutorais de Bretones (2006), Leite (2006), Sobreira (2006) e Langhi (2009a). Durante esse intervalo, Bretones e Megid Neto (2005) organizaram uma base de dados que foi importante para a divulgação de teses e dissertações sobre o tema em todo o país, fato a ser considerado.

Além disso, em 2004 ocorreu o lançamento da RELEA - Revista Eletrônica Latino-Americana de Educação em Astronomia, consolidando-se como uma das principais fontes de consulta em língua portuguesa e castelhana no hemisfério sul sobre pesquisas do campo da Educação em Astronomia.

Entendemos que 2009 tenha sido um ano importante para o ensino e a pesquisa em Educação em Astronomia no país, pois a UNESCO o definiu como o Ano Internacional da Astronomia (AIA2009 ${ }^{2}$ ). Augusto Damineli, o representante brasileiro na União Astronômica Internacional e o coordenador do ano internacional da

\footnotetext{
${ }^{2} \mathrm{O}$ ano de 2009 foi escolhido em virtude das comemorações dos 400 anos das descobertas astronômicas mais importantes de Galileu, como a identificação de corpos celestes revolucionando em torno de Júpiter, as luas galileanas ou, como denominadas pelo cientista, astros mediceus.
} 
Astronomia no Brasil, saudou a todos através de um vídeo divulgado em janeiro daquele ano:

\begin{abstract}
A ONU declarou 2009 como o ano internacional da Astronomia. O governo brasileiro teve um papel decisivo nessa declaração, e aqui no Brasil se montou uma grande rede de divulgação científica coordenada por cientistas, astrônomos amadores e educadores para oferecer ao público atividades de observação do céu, palestras, shows de planetários, durante todo o ano. O que queremos é usar o fascínio que a Astronomia desperta nas pessoas para aproximá-las da ciência, para difundir uma mentalidade científica, para atrair jovens para a carreira de pesquisador. Na Astronomia se processam revoluções a cada década. No entanto, nosso cidadão ainda vive o imaginário antiquado de um céu completamente desconectado da terra. No entanto, já faz 500 anos que nós sabemos que a terra está no céu. Depois disso, descobrimos muitas maneiras pelas quais o céu está na terra. Toda energia que aqui circula veio de fora do planeta, toda matéria que aqui está veio das estrelas que já morreram. Nós somos poeira de estrelas. $O$ nosso cotidiano tem relações muito mais profundas com um cenário muito amplo que nós não descobrimos com facilidade. 2009 é o ano para as pessoas redescobrirem suas ligações, por que toda vez que exploramos o espaço lá fora, o nosso espaço interno se amplia, se reconecta de diferentes formas e isso é fundamental para a cultura humana. Nós contemos o universo que nos contém. Como representante da União Astronômica Internacional para o ano de 2009 no Brasil, quero convidar a todos para participarem ativamente das atividades programadas pela rede e procurar no site as atividades para a sua região específica. Que todos tenham um excelente 2009 e que procurem as suas ligações com o universo. Esse é o ano para fazer isso (DAMINELI, 2009, sem paginação).
\end{abstract}

Durante 2009, vimos surgir inúmeras atividades sobre a Astronomia e seu ensino em vários locais pelo mundo. O P5 comenta sobre o "boom" de eventos relacionados à Astronomia no Brasil.

P5: [...] Acho que depois do Ano Internacional da Astronomia principalmente, foi um "boom" maior, pois antes tínhamos coisas mais esporádicas. Parece-me que temos mais cursos nessa temática hoje do que antes. Aumentou a oferta, quer dizer, aumentou talvez o interesse das pessoas, pois foram ver de repente, ou participaram de algumas atividades, mesmo sem querer, de algumas atividades que envolveram o AIA e acabaram se envolvendo mais.

Entre as várias atividades realizadas no Brasil no AIA2009, a organização de nós locais e a criação dos EREA (Encontro Regional de ensino de Astronomia) são as que mais chamam a nossa atenção devido a sua contínua existência. Os EREA, por exemplo, atingiram até o momento a marca de mais de 40 eventos realizados pelo país (Quadro 4). O P4 comenta sobre algumas das várias atividades relacionadas aos EREA: 
P4: [...] mais recentemente, de 2009 para cá, tivemos um programa de cursos onde chamamos Encontros Regionais de ensino de Astronomia, o EREA, e o Paraná é o estado que mais tem aproveitado essas ofertas desses cursos, pois eles têm um custo quase que zero para o núcleo regional, pois entramos com as passagens dos palestrantes, com material de consumo utilizado, doamos livros, planisférios, lunetas... conseguimos comprar 20000 lunetas, os chamamos galileoscópios em 2009, já distribuímos em torno de 16000 lunetas e essas últimas estamos distribuindo somente presencialmente, montando com os professores e ensinando a usar. Ampliamos também a questão de cursos na área de astronáutica, selecionamos um conjunto de alunos e seus professores para capacitação na área de astronáutica, incluímos também um evento na área de energia nos últimos quatro anos.

\begin{tabular}{|c|c|c|c|c|c|}
\hline $\mathbf{N}^{\mathbf{o}}$ & Local & $\begin{array}{l}\text { Período } \\
\text { (continua) }\end{array}$ & $\mathbf{N}^{\mathbf{o}}$ & Local & $\begin{array}{l}\text { Período } \\
\text { (conclusão) }\end{array}$ \\
\hline I & Foz do Iguaçu (PR) & $16-19 / 09 / 2009$ & XXVII & Maringá (PR) & $28-31 / 05 / 2012$ \\
\hline II & Bauru (SP) & $24-30 / 10 / 2009$ & XXVIII & Belo Horizonte (MG) & $07-10 / 06 / 2012$ \\
\hline III & Sobral (CE) & $19-21 / 11 / 2009$ & XXIX & Toledo (PR) & $19-21 / 07 / 2012$ \\
\hline IV & Porto Alegre (RS) & $24-26 / 03 / 2010$ & $\mathrm{XXX}$ & Natal (RN) & $23-27 / 07 / 2012$ \\
\hline V & Iepê (SP) & $21-24 / 04 / 2010$ & XXXI & Foz do Iguaçu (PR) & $19-22 / 09 / 2012$ \\
\hline VI & Limoeiro do Norte (CE) & $16-19 / 06 / 2010$ & XXXII & Vassouras (RJ) & $07-11 / 08 / 2012$ \\
\hline VII & Caucáia (CE) & $18-21 / 08 / 2010$ & XXXIII & Cascavel (PR) & $02-04 / 10 / 2012$ \\
\hline VIII & Foz do Iguaçu (PR) & $21-25 / 09 / 2010$ & XXXIV & Teresina (PI) & $29 / 10-01 / 11 / 2012$ \\
\hline IX & Toledo (PR) & $06-09 / 10 / 2010$ & XXXV & Maceió (AL) & $5-7 / 12 / 2012$ \\
\hline $\mathrm{X}$ & Campo Grande (MS) & $13-16 / 10 / 2010$ & XXXVI & Pitanga (PR) & $20-23 / 03 / 2013$ \\
\hline XI & São Carlos (SP) & $20-23 / 10 / 2010$ & XXXVII & Lajeado (RS) & $18-20 / 04 / 2013$ \\
\hline XII & Recife (PE) & $10-12 / 11 / 2010$ & XXXVIII & Bauru (SP) & $08-11 / 05 / 2013$ \\
\hline XIII & São Paulo (SP) & $10-12 / 02 / 2011$ & XXXIX & Pres. Prudente (SP) & $23-25 / 05 / 2013$ \\
\hline XIV & Jaraguá do Sul (SC) & $09-11 / 03 / 2011$ & $40^{\circ} *$ & Batatais (SP) & $10-13 / 07 / 2013$ \\
\hline $\mathrm{XV}$ & Santo André (SP) & $25-27 / 04 / 2011$ & $41^{\circ}$ & Jundiaí (SP) & $24-27 / 07 / 2013$ \\
\hline XVI & Ji-Paraná (RO) & $18-21 / 05 / 2011$ & $42^{\circ}$ & Videira (SC) & $01-03 / 08 / 2013$ \\
\hline XVII & Belo Horizonte (MG) & $26-28 / 05 / 2011$ & $43^{\circ}$ & Marília (SP) & 03-05/10/2013 \\
\hline XVIII & Ponta Grossa (PR) & $06-11 / 06 / 2011$ & $44^{\circ}$ & Santa Fé - Argentina & $07-08 / 10 / 2013$ \\
\hline XIX & Ubatuba (SP) & 04-08/07/2011 & $45^{\circ}$ & Anápolis (GO) & $16-18 / 01 / 2014$ \\
\hline $\mathrm{XX}$ & Pato Branco (PR) & $20-23 / 07 / 2011$ & $46^{\circ}$ & Pres. Prudente (SP) & $20-22 / 03 / 2014$ \\
\hline XXI & Cascavel (PR) & $25-27 / 08 / 2011$ & $47^{\circ}$ & Umuarama (PR) & $09-11 / 04 / 2014$ \\
\hline XXII & Pelotas (PR) & $02-05 / 11 / 2011$ & $48^{\circ}$ & João Pessoa (PB) & 29/04-01/05/2014 \\
\hline XXIII & Assis (SP) & $10-11 / 11 / 2011$ & $49^{\circ}$ & Oswaldo Cruz (SP) & $11-13 / 06 / 2014$ \\
\hline XXIV & Arapoti (PR) & $30 / 11-3 / 12 / 2011$ & $50^{\circ}$ & Pitanga (PR) & $24-27 / 06 / 2014$ \\
\hline $\mathrm{XXV}$ & $\begin{array}{l}\text { Feira de } \\
\text { Santana (BA) }\end{array}$ & $28-31 / 03 / 2012$ & $51^{\circ}$ & Adamantina (SP) & 09-11/07/2014 \\
\hline XXVI & Pinhais (PR) & $27-30 / 04 / 2012$ & $52^{\circ}$ & Piracicaba (SP) & $16-18 / 07 / 2014$ \\
\hline
\end{tabular}

Quadro 4 - EREA realizados entre 2009 e Janeiro de 2014.

Fonte: Sítio oficial do EREA na internet. (http://www.erea.ufscar.br).

*A numeração romana deixou de ser utilizada a partir do $40^{\circ}$ evento. 
Infelizmente, o sitio oficial do AIA no Brasil foi desabilitado, o que impossibilita um levantamento mais detalhado das diversas atividades realizadas em 2009. Voltaremos a comentar sobre a grande rede citada pelo professor Damineli em sua saudação ao longo deste trabalho.

Pudemos, até então, refletir sobre como várias ações se consolidaram no país graças à análise histórica do desenvolvimento dessa linha de pesquisa, de 1973 até recentemente. Buscamos sintetizar as mais importantes na seguinte lista:

i. Surgimento de pesquisadores interessados na Astronomia, que fomentaram as primeiras ações relacionadas ao ensino dessa ciência no país;

ii. Criação da comissão de ensino de Astronomia dentro da SAB;

iii. Elaboração dos PCN, que oficializaram o ensino de certos conteúdos da Astronomia no currículo escolar;

iv. Surgimento de eventos como o EBEA, a OBA, o SNEA e o EREA;

v. Lançamento da RELEA;

vi. Gradativo aumento do número de trabalhos em eventos, além de teses e dissertações;

vii. $\mathrm{O}$ ano internacional da Astronomia, que pode ser considerado um fator catalisador para o surgimento de novas pessoas interessadas nessa linha de pesquisa;

viii. A manutenção de alguns nós locais provenientes do AIA2009, que poderão vir a se tornar futuros centros de referência no país.

Recentemente, Longhini et al. (2013) realizaram um estudo sobre o atual perfil dos pesquisadores interessados pelo campo de Educação em Astronomia no país. Através de buscas sistemáticas no sistema Lattes, os autores encontraram 187 pesquisadores segundo os seguintes critérios: i) apresentou projeto sobre a Educação em Astronomia; ou ii) foi autor ou coautor de livro desse campo; ou iii) orientou trabalhos de mestrado ou doutorado nesse campo; ou iv) foi autor de tese ou dissertação nesse campo. Após a análise dos currículos, concluíram que 132 deles são formados em Física, 128 são pesquisadores na região sudeste, 163 se formaram em instituição pública, 131 se pós-graduaram na região sudeste e 113 se tornaram doutores após 2000. De certa forma, esses dados refletem a realidade de nossos entrevistados, pois são em maioria atuantes na região sudeste, tendo parte deles defendido recentemente seus doutorados.

Ainda sobre o presente, o P3 comenta:

P3: O que está recente é o segundo SNEA. O Simpósio Nacional de Educação em Astronomia. O II SNEA me deixou bastante motivado. Porque teve uma pausa aí dos anteriores EBEAs, Encontro Brasileiro de ensino de Astronomia, foi até 2004 e parou e ano passado foi retomado, em 2011 retorna então os encontros específicos de Educação em Astronomia. Não que outros eventos ou revistas não apresentassem trabalhos sobre o ensino de Astronomia. É especificamente. Acho que a área, bom, vamos chamar de pseudoárea, ela oficialmente não é uma área, mas vamos chamar assim, vamos ser otimistas, a área está ganhando força e isso me 
deixa bastante contente, porque a gente vê que essa luta é antiga, tomou rumos diferentes, interesses diferentes, mas acho que agora a preocupação na produção de anais registrados, com ISSN, com grupos e comitês de avaliações de trabalhos, pareceristas, enfim, tomando uma forma de um grupo que quer assumir uma madureza maior, para dar uma forma e uma identidade a Educação em Astronomia. Então é um momento histórico, único, pois até então a Educação em Astronomia acabava sendo um apêndice. Eram artigos publicados periodicamente em revistas diferenciadas e agora no Brasil temos a RELEA, embora Latinoamericana. No Brasil tem o boletim da SAB, mas que traz pequenos resumos e não artigos completos. A RELEA é a revista que tenta reunir os artigos, mas mesmo assim percebemos que temos um longo caminho a trilhar. Mesmo a RELEA precisa de mais artigos. O SNEA está na segunda edição. Talvez melhorar algumas divisões internas que existem aí, especificar bem o trabalho de astrônomo profissional, astrônomo amador, planetários e observatórios, Educação ou ensino de Astronomia, deixar claro essas identidades, essas entidades. Eu estou satisfeito do início desse caminho longo a ser trilhado. Acho que se manter o foco, essa preocupação... é o que a gente viu no início das outras áreas, nos $S N E F$, na SBF, tudo tem um começo difícil e tumultuado. Até o universo teve um começo tumultuado e continua até hoje, não é?

Com a reflexão deixada pelo P3, que nos dá uma visão geral da atual situação da pesquisa em ensino de Astronomia no país, passamos a estudar mais profundamente os nossos entrevistados, no intuito de investigar quem são e de onde falam.

\section{Considerações Finais}

Relatamos aqui resultados parciais de pesquisa que visou investigar as concepções de investigadores da área de educação em Astronomia com relação à formação inicial e continuada de professores para o ensino dessa ciência. Em decorrência do estudo realizado, pudemos destacar as memórias dos pesquisadores sobre a consolidação desse campo de pesquisa.

É válido ressaltar que prováveis limitações se fizeram presentes ao longo do desenvolvimento da pesquisa. A principal, como entendemos, diz respeito ao número reduzido de pesquisadores entrevistados, fato que pode, de certa maneira, levarmo-nos a indagar sobre a real representatividade que eles proporcionam a essa área de pesquisa. Apesar disso, reconhecemos que o campo de pesquisa em Educação em Astronomia consolida-se gradativamente no país, e que apenas recentemente o crescimento do número de pesquisadores tem alavancado, provavelmente, pela inserção da Astronomia nos Parâmetros Curriculares Nacionais, em 1998, e também pelo acontecimento do Ano Internacional da Astronomia, em 2009.

Além disso, não pretendemos que os resultados apresentados sejam aceitos pelo leitor como a história "completa" do crescimento e consolidação da área. Nesse sentido, o exposto por nós representa trechos de uma história que poderá continuar a ser desvelada por outros pesquisadores em outras condições de pesquisa.

Esperamos que a memória da formação do campo de pesquisa da Educação em Astronomia no Brasil possa contribuir para a análise de possíveis soluções para as atuais demandas relacionadas ao ensino dessa ciência no país, principalmente em relação à formação inicial e continuada de professores com vistas ao ensino dessa ciência. 


\section{Referências}

ADORNO, T. W. Tabus acerca do magistério. In: ADORNO, T. W. Educação e emancipação. 4. ed., São Paulo: Paz e Terra, 2006.

BARDIN, L. Análise de Conteúdo, Portugal: Edições 70, 2000.

BISCH, S. M. Astronomia no ensino Fundamental: Natureza e conteúdo do conhecimento de estudantes e professores. 1998. 301 f. Tese (Doutorado em Educação) - Universidade de São Paulo, São Paulo. 1998.

BONAMINO, A.; MARTÍNEZ, S. A., Diretrizes e parâmetros curriculares nacionais para o ensino fundamental: a participação das instâncias políticas do estado, Educação e Sociedade, v.23, n.80, p.368-385, 2002.

BRETONES, P. S. A Astronomia na formação continuada de professores e o papel da racionalidade prática para o tema da observação do céu. 2006. 281 f. Tese (Doutorado em Ciências) - Instituto de Geociências da UNICAMP, Campinas. 2006.

BRETONES, P. S. Disciplinas introdutórias e Astronomia nos cursos superiores do Brasil. 1999. 187 p. Dissertação (Mestrado em Educação) - Instituto de Geociências da UNICAMP, Campinas. 1999.

BRETONES, P. S.; MEGID NETO, J. Tendências de Teses e Dissertações sobre Educação em Astronomia no Brasil. Boletim da Sociedade Astronômica Brasileira, v.24, n.2, p.35-43, 2005.

CANIATO, R. Ato de fé ou conquista do conhecimento? Um episódio na vida de Joãozinho da Maré. Boletim da Sociedade Astronômica Brasileira, a.6, n.2, p.31-37, 1983.

CANIATO, R. Ideário e prática de uma proposta brasileira para o ensino de Física. In: SIMPÓSIO NACIONAL DE ENSINO DE FÍSICA, 6., 1985, Niterói. Atas..., Niterói: $\mathrm{SAB}, 1985$.

CANIATO, R. Meus caminhos no ensino de Astronomia, In: SIMPÓSIO NACIONAL DE EDUCAÇÃO EM ASTRONOMIA, 1., 2011, Rio de Janeiro. Atas..., Rio de Janeiro: UNIRIO, 2011. Disponível em: <http://snea2011.vitis.uspnet.usp.br>. Acessado em: 27 set. 2012.

CANIATO, R. Um Projeto Brasileiro para o Ensino de Física. 1973. 586 p. Tese (Doutorado) - UNESP, Rio Claro. 1973.

DAMINELI, A. Saudação Augusto Damineli AIA 2009. 2009. Disponível em <www.youtube.com>. Acessado em 13 nov. 2012. Sem paginação.

FERES, G. R. A pós-graduação na área de Ensino de Ciências no Brasil: uma leitura a partir da teoria de Bourdieu. 2010. 290 f. Tese (Doutorado em Educação para a Ciência) - Universidade Estadual Paulista - Faculdade de Ciências, Bauru. 2010. 
IACHEL, G. Os caminhos da formação de professores e da pesquisa em ensino de Astronomia. 2013. 201 f. Tese (Doutorado em Educação para a Ciência) - Faculdade de Ciências da UNESP, Bauru. 2013.

IACHEL, G.; NARDI, R. Algumas tendências das publicações relacionadas à Astronomia em periódicos brasileiros de ensino de Física nas últimas décadas. Revista Ensaio, v.12, n.2, p.225-238, 2010.

LANGHI, R. Astronomia nos anos iniciais do ensino fundamental: repensando a formação de professores. 2009. 370 p. Tese (Doutorado em Educação a para Ciência) Faculdade de Ciências - UNESP, Bauru. 2009.

LANGHI, R. Um estudo exploratório para a inserção da Astronomia na formação de professores dos anos iniciais do ensino Fundamental. 2004. 240 f. Dissertação (Mestrado em Educação para a Ciência) - Faculdade de Ciências - UNESP, Bauru. 2004.

LEITE, C. Formação do professor de Ciências em Astronomia: uma proposta com enfoque na espacialidade. 2006. 274 f. Tese (Doutorado em Educação) - Faculdade de Educação, Universidade de São Paulo, São Paulo. 2006.

LIVI, S. H. B. ensino de Astronomia no $1^{\circ}$ e $2^{\circ}$ grau (relatório). In: SIMPÓSIO NACIONAL DE ENSINO DE FÍSICA, 10., 1993, Londrina. Atas..., Londrina: Sociedade Brasileira de Física, 1993. p.96-8.

LIVI, S. H. B. ensino de Astronomia para professores do $1^{\circ}$ e $2^{\circ}$ grau, In: SIMPÓSIO NACIONAL DE ENSINO DE FÍSICA, 7., 1987, São Paulo. Resumos..., São Paulo: Sociedade Brasileira de Física, 1987.

LONGHINI, M. D.; GOMIDE, H. A.; FERNANDES, T. C. D. Quem somos nós? Perfil da comunidade acadêmica brasileira na Educação em Astronomia, Ciência \& Educação, v.19, n.3, p.739-759, 2013.

MARRONE, J. J. Um perfil da pesquisa em ensino de Astronomia no Brasil a partir da análise de periódicos de ensino de Ciências. 2007. Dissertação (Mestrado Ensino de Ciências e Educação Matemática) - Universidade Estadual de Londrina, Londrina/PR. 2007.

MEES, A. A. Astronomia: Motivação para o ensino de Física na $8^{a}$ Série. 132 f. Dissertação (Mestrado em ensino de Física) - Instituto de Física - Universidade Federal do Rio Grande do Sul, Porto Alegre. 2004.

NARDI, R. (Org.). X Simpósio Nacional de Ensino de Física: tempo de avaliação. In: SIMPÓSIO NACIONAL DE ENSINO DE FÍSICA, 10., 1993, Londrina. Atas..., Londrina: Sociedade Brasileira de Física, 1993.

NARDI, R. A área de ensino de Ciências no Brasil: fatores que determinaram sua constituição e suas características segundo pesquisadores brasileiros. 2005. 166 f. Tese (Livre-docência) - Universidade Estadual Paulista. Faculdade de Ciências, Bauru. 2005. 
NASCIMENTO, S. S.; HAMBURGER, E. W. Fundamentos de Astronomia e gravitação para professores de $1^{\mathrm{a}}$ à $4^{\mathrm{a}}$ séries, In: SIMPÓSIO NACIONAL DE ENSINO DE FÍSICA, 7., 1987, São Paulo. Resumos..., São Paulo: Sociedade Brasileira de Física, 1987.

NEVES, M. C. D. ensino de Astronomia no $1^{\circ}$ e $2^{\circ}$ grau (relatório). In: SIMPÓSIO NACIONAL DE ENSINO DE FÍSICA, 9., 1991, São Carlos. Atas..., São Carlos: Sociedade Brasileira de Física, 1991. p.134-7.

REZENDE, F.; OSTERMANN, F. Olimpíadas de ciência: uma questão em prática, Ciência \& Educação, v.18, n.1, p.245-256, 2012.

SOBREIRA, P. H. A. Cosmografia Geográfica: a Astronomia no ensino de Geografia, [Tese de Doutorado], São Paulo/SP, Universidade de São Paulo, USP, 239 p., 2006.

TREVISAN, R. H. Atuação do grupo de Astrofísica da UEL e sua ampliação na criação da comissão de ensino de Astronomia junto a SAB, In: SIMPÓSIO NACIONAL DE EDUCAÇÃO EM ASTRONOMIA, 1, Rio de Janeiro, 2011, Atas..., Rio de Janeiro: UNIRIO, 2011. Disponível em: <http://snea2011.vitis.uspnet.usp.br>. Acessado em: 27 set. 2012. 


\section{Apêndice A - Relato histórico sobre os EBEA}

O trecho a seguir representa um relato sobre a História dos EBEA por uma pessoa que participou ativamente dos encontros. O referido indica possíveis razões para a separação do evento em outros dois, um voltado para atender interessados na área de Educação e o outro para a demanda dos técnicos envolvidos em Planetários. Não é possível precisar quando o relato foi escrito, todavia a leitura indica que sua elaboração ocorreu entre outubro de 2003 e julho de 2004. Não ocorreram edições gráficas ou textuais, nem mesmo correções ortográficas possíveis, na versão original recebida por email em 01/10/2012.

As reuniões que ocorreram anteriormente foram organizadas pela ABP e pela SBEA com participação de alguns representantes da CESAB e/ou da SAB (em Campinas, Porto Alegre, Belém, Rio de Janeiro e Belo Horizonte), e tinham por objetivo reunir em um mesmo evento os profissionais envolvidos com o ensino da Astronomia e principalmente os profissionais que atuam em planetários. O último encontro desses profissionais foi em Fortaleza, em 2002, ocasião em que se decidiu separar os eventos.

Em 1999, no Rio de Janeiro, houve um pequeno movimento favorável à separação desses encontros, devido a pouca atração que eles surtiam nos profissionais não vinculados a planetários, pois o evento da $\mathrm{ABP}$ estava se fortalecendo com a crescente participação e contribuições técnicas dos planetaristas e, por outro lado, ocorria o esvaziamento de outros profissionais acadêmicos do ensino de Astronomia (principalmente da $\mathrm{SAB}$ ), pois não havia anais ou boletins com resumos e/ou trabalhos completos. O nível de qualidade dos trabalhos de ensino de Astronomia era decadente, as palestras eram discursos floreados de professores sabidamente sem ações concretas no ensino, enquanto os planetaristas todos os anos apresentavam (e continuam apresentando) relatórios de diretoria, com números de sessões, público, número de alunos nos cursos e outras futilidades.

Os eventos se mantiveram unidos pelos dois anos seguintes, porém enfraquecidos pelas discórdias e rivalidades entre grupos opositores iniciados no Rio de Janeiro, que refletiu em ausências de colegas de alguns planetários. Finalmente a separação ocorreu em 2002, em Fortaleza, em um evento fraco em todos os níveis, sem nenhuma manifestação contrária, quando contamos com apenas 4 apresentações de trabalhos de ensino de Astronomia, sendo que apenas duas trouxeram temas adequados ao evento. Os eventos estavam se tornando caros, pois os organizadores esperavam a participação de cerca de 100 pessoas, no entanto, não compareciam mais de 30 pessoas e o público geral sumiu.

Os eventos que contaram com maiores participações aconteceram em Belém e no Rio de Janeiro, pois o público compareceu para assistir palestras e cursos, além disso, há uma maior concentração de profissionais de Astronomia no Rio de Janeiro, do que nas outras cidades onde ocorreram os outros encontros. Por esta razão é que queremos fazer um encontro com bastante visibilidade em São Paulo, e que seja um marco nesta nova fase separada da ABP. 
Os encontros anteriores foram:

I ENCONTRO BRASILEIRO DE ENSINO DE ASTRONOMIA I REUNIÃO DA ASSOCIAÇÃO BRASILEIRA DE PLANETÁRIOS Campinas - SP / 25 a 28 de outubro de 1996

II ENCONTRO BRASILEIRO DE ENSINO DE ASTRONOMIA II REUNIÃO DA ASSOCIAÇÃO BRASILEIRA DE PLANETÁRIOS Porto Alegre - RS / 08 e 09 de novembro de 1997

III ENCONTRO BRASILEIRO DE ENSINO DE ASTRONOMIA III REUNIÃO DA ASSOCIAÇÃO BRASILEIRA DE PLANETÁRIOS Belém - PA / 08 a 11 de setembro de 1998

IV ENCONTRO BRASILEIRO DE ENSINO DE ASTRONOMIA IV REUNIÃO DA ASSOCIAÇÃO BRASILEIRA DE PLANETÁRIOS Rio de Janeiro - RJ / 01 a 04 de dezembro de 1999

V ENCONTRO BRASILEIRO DE ENSINO DE ASTRONOMIA V REUNIÃO DA ASSOCIAÇÃO BRASILEIRA DE PLANETÁRIOS Belo Horizonte / Ouro Preto - MG / 21 a 24 de novembro de 2000

VI ENCONTRO BRASILEIRO DE ENSINO DE ASTRONOMIA VI REUNIÃO DA ASSOCIAÇÃO BRASILEIRA DE PLANETÁRIOS

Florianópolis - SC / 22 a 26 de outubro de 2001

\section{ENCONTRO BRASILEIRO DE ENSINO DE ASTRONOMIA VII REUNIÃO DA ASSOCIAÇÃO BRASILEIRA DE PLANETÁRIOS} Fortaleza - CE / 30 de outubro a 2 de novembro 2002

O último da ABP, já separado do EBEA foi:

VIII REUNIÃO DA ASSOCIAÇÃO BRASILEIRA DE PLANETÁRIOS Santa Maria - RS / 23 a 26 de outubro 2003

O próximo EBEA que queremos fazer será em São Paulo, para que ele não desapareça, pois durante dois anos não houve manifestação de nenhuma entidade interessada em realizá-lo, somente a SBEA o quer. O período é provisório:

\section{ENCONTRO BRASILEIRO DE ENSINO DE ASTRONOMIA}

São Paulo - SP / 5 a 11 de julho de 2004

"O ensino, a divulgação e a popularização da Astronomia em debate"

Pretendemos publicar anais dos resumos dos trabalhos em CD-ROM e realizar algum(ns) passeios técnicos em São Paulo, por entidades/locais que realizam ensino de Astronomia. Gostaríamos também de oferecer cursos e palestras ao público em geral. 